\title{
Sensory properties linked to fat content and tasting temperature in cottage cheese
}

\author{
Christophe Martin $^{1} \cdot$ Rachel Schoumacker ${ }^{1}$ - Doris Bourjade ${ }^{1}$. \\ Thierry Thomas-Danguin ${ }^{1}$ - Elisabeth Guichard ${ }^{1}$. \\ Jean-Luc Le Quéré ${ }^{1}$ - Hélène Laboure ${ }^{1,2}$
}

Received: 7 April 2016 /Revised: 22 July 2016 / Accepted: 31 July 2016 /

Published online: 7 September 2016

(C) INRA and Springer-Verlag France 2016

\begin{abstract}
There is a growing interest in developing low-fat products in response to increased consumer demand. However, fat reduction often leads to low sensory acceptability by consumers. The identification of the sensory characteristics impacted by the reduction of fat is a first step to choose the most appropriate strategy to offset the adverse effects of a fat reduction. This work examined the impact of fat content and tasting temperature on the sensory characteristics of cottage cheese. A conventional sensory profile was conducted to characterize seven cottage cheeses at two tasting temperatures $\left(7\right.$ and $\left.15^{\circ} \mathrm{C}\right)$. Five products differed based on their fat content $(0,1,3,8$, and $11 \%$ ), while the last two contained $1 \%$ fat and were flavored by the addition of 0.07 and $0.13 \%$ cream flavor. Differences among the cottage cheeses varying in fat content were based on a range of differences related to aroma (mainly a cream aroma), taste (mainly bitterness), trigeminal sensation (astringency), and texture (greasy film). The tasting temperature did not impact taste, aroma, or astringency. However, thickness was strongly modified by tasting temperature, regardless of the fat content of the different cottage cheeses. Moreover, this study suggests that fattiness is difficult to define and that this descriptor could be advantageously replaced by greasy film which was shown to be highly reliable in discriminating between various fat contents in cottage cheese.
\end{abstract}

Keywords Fat content $\cdot$ Sensory profile $\cdot$ Dairy product $\cdot$ Cottage cheese

Martin Christophe and Schoumacker Rachel contributed equally to this work.

Christophe Martin

christophe.martin@dijon.inra.fr

1 Centre des Sciences du Goût et de l'Alimentation CNRS, INRA, University Bourgogne

Franche-Comté, F-21000 Dijon, France

2 AgroSup Dijon, 21000 Dijon, France 


\section{Introduction}

Health concerns related to fat overconsumption have led the food industry to design products with reduced-fat contents. However, developing low-fat food without altering their sensory properties is often challenging because fat contributes to the overall quality of the products and, thus, influences their acceptability. A classical strategy for increasing acceptability of low-fat foods is to rebalance the sensory characteristics impacted by fat reduction to keep the global sensory profile of the reduced-fat foods unchanged. To successfully employ this strategy of compensation, one needs to fully understand how fat is perceived in the studied products or, more precisely, to have a perfect knowledge of the sensory characteristics impacted by the reduction of fat. Fat perception is considered multimodal and involves in-mouth tactile sensations and olfactory, taste, and somatosensory cues (Mattes 2009). Indeed, sensory discrimination of samples varying in fat content is likely based on differences in the perception of several descriptors that rely on different sensory modalities, among which textural cues are thought to be predominant. Nevertheless, Le Calvé et al. (2015) recently showed that the most efficient sensory dimensions involved in the ability to discriminate among samples varying in fat content depend on the type of food product. For instance, in white sauces, taste and texture were found to be the most effective modalities for fat level sensory discrimination below $15 \%$ or above $30 \%$ fat content, whereas olfactory cues prevail to discriminate fat content variation in between 15 and $30 \%$. In milk $(0$, 2.7 , and $3.8 \%$ fat) and stirred yoghurt ( 0.5 and $1.75 \%$ fat), taste and texture perceptions did not favor the discrimination between fat levels in plain products, whereas visual and olfactory cues did. Some authors have examined the effect of the tasting temperature of the food on fat perception. Here again, the results differed according to the products. However, for dairy products, it seems that differences between samples varying in fat content are more noticeable at higher tasting temperatures, and a recent study showed that detection and differential thresholds for fat in cottage cheeses were lower at $15{ }^{\circ} \mathrm{C}$ than at $7{ }^{\circ} \mathrm{C}$ (Engelen et al. 2003, Mela 1988, Schoumacker et al. 2016).

This work aimed to provide a full description of the sensory characteristics of cottage cheeses varying in fat content. The main objective was to identify the characteristics linked to the perception of fat content, with the idea that these characteristics could be modulated to compensate for the effects of fat reduction in reduced-fat cottage cheeses. A secondary objective was to study the extent to which tasting temperature modified the sensory profiles of the different cottage cheeses, especially for sensory characteristics related to fat content. This last objective was motivated by the fact that in everyday life, cottage cheese can be consumed at very different temperatures depending on the context, namely, straight from the refrigerator or several tens of minutes after removal from the refrigerator, as in a cafeteria.

Moreover, the identification of the main sensory characteristics linked to fat content and their modification in relation to tasting temperature will provide better insights on the multimodal aspects of fat perception in dairy products. 


\section{Materials and methods}

\subsection{Experimental conditions}

All sessions took place in an air-conditioned $\left(21+/-2^{\circ} \mathrm{C}\right)$ sensory testing room of the ChemoSens platform (Centre des Sciences du Goût et de l'Alimentation, INRA, Dijon) using standardized booths equipped with computers. All tests were conducted under white light in the room and booths. Data acquisition was performed using the FIZZ software (Biosystemes, Couternon, France).

\subsection{Panelists}

Thirty-two subjects with previous experience in sensory descriptive analyses (participation in at least one study involving sensory profile) were invited to participate in two selection sessions. From this group, the 16 best panelists were selected based on the results achieved for several tests intended to assess the following abilities : (i) olfactory capabilities (ETOC, European test of olfactory capabilities, Thomas-Danguin et al. 2003), (ii) the ability to identify the five basic tastes and to classify sapid and aroma solutions according to their perceived intensity, (iii) the ability to focus one's attention while performing a complex task (Bourdon T.I.B. test, Swets \& Zeitlinger BV, Calisse, The Netherlands), and (iv) the ability to produce appropriate terms to describe the sensations perceived while tasting the three samples of plain dairy products (cottage cheese, yoghurt, Petit-Suisse cheese). The selected panel was composed of ten women and six men, ages 42 to 66 years (mean age, 55 years). These panelists signed an informed consent form and were compensated for their participation. They came to the laboratory over 3 months, twice a week at lunchtime for a 1.5-h session, and they were asked to not eat or drink anything except water, not smoke, and not brush their teeth for $1 \mathrm{~h}$ prior to the session.

\subsection{Products}

Seven cottage cheeses were characterized at two tasting temperatures ( 7 and $15{ }^{\circ} \mathrm{C}$ ). Five differed in their fat content $(0,1,3,8$, and $11 \%$, noted as F0, F1, F3, F8, and F11, respectively), while the last two contained $1 \%$ fat and 0.07 and $0.13 \%$ cream flavor formulated by Firmenich SA (Genève, Suisse) and were noted as F1+ and F1++, respectively. This flavor was formulated with seven aroma compounds in medium chain triglycerides (MCT) solvent. The F0 and F8 samples were commercial cottage cheeses (Paturage ${ }^{\circledR}$ Intermarché, France). Mixtures of these two commercial products were used to obtain the F1 and F3 samples. Double cream containing $30 \%$ fat (Paturage ${ }^{\circ}$, Intermarché, France) was added to F8 to obtain the F11 sample. The two flavored cottage cheeses $(\mathrm{F} 1+$ and $\mathrm{F} 1++)$ were added to the set of samples tested to examine the influence of the added cream flavor on fat perception. The flavoring was made at least $24 \mathrm{~h}$ before the assessment (the time required for equilibration). In order to obtain a good distribution of the added flavor into the cottage cheese, the mixture was manually whipped during $1 \mathrm{~min}$. Although not flavored, all of the other products were also whipped during this same 1-min period. A few hours before the evaluation, 
all products were whisked for $30 \mathrm{~s}$ and placed in coded disposable plastic cups with lids ( $50 \mathrm{~g}$ of cottage cheese per cup). Samples were then stored for at least $1.5 \mathrm{~h}$ in cold rooms at the target tasting temperature $\left(7\right.$ or $\left.15^{\circ} \mathrm{C}\right)$. The actual sample temperatures were systematically recorded: for the low and high temperatures, the samples were served at $6.8{ }^{\circ} \mathrm{C}(+/-0.1)$ and $14.9{ }^{\circ} \mathrm{C}(+/-0.1)$, respectively. Viscosity measurements were performed with a rotating shear rate imposed rheometer (Rheomat RM200, Lamy Rheology, Champagne au Mont d'Or, France) equipped with a coaxial cylinder (MSDIN 11). The measurements were done using a share rate of $10 \mathrm{~s}^{-1}$. Titratable acidity was determined according to the method described in ISO/TS 11869 (2012). The results were expressed in Dornic degrees $\left({ }^{\circ} \mathrm{D}\right)$, and the amount of lactic acid was calculated using the following relationship: $1^{\circ} \mathrm{D}=0.1 \mathrm{~g}$ lactic acid.

\subsection{Sensory profile}

Flavor, texture, trigeminal sensations, and after swallowing sensations were described and evaluated using a conventional sensory profile (ISO 6564: 1985). Sixteen sessions were devoted to the development of a vocabulary to describe the sensory characteristics and to the training of panelists. The quantitative descriptive analysis began with the development of a common list of descriptors that comprehensively and accurately described the sensory characteristics of the cottage cheeses. The selection of the attributes included in the final list was based on a consensus procedure. Panelists were trained in the quantification of the selected descriptors using visual analog scales. They make a mark on a line to indicate the intensity of each characteristic ( 0 to 10 scores, real number with one decimal). Late in the training sequence, a series of trial evaluations were performed to evaluate panelist performance and to determine the end of the training. The usual performance criteria were considered: discriminatory power (ability of the panelists to differentiate between the products based on their attributes), agreement within the group (how an individual agrees, on average, with the panel as a whole), and repeatability (ability to provide the same attribute scores to the same product). The methods used to monitor the performance of a quantitative sensory panel are described in ISO 11132 (2012). The sixteen training sessions yielded a final list of 14 attributes that exhibited significant differences among the products: perceived temperature, thickness, remaining quantity in mouth, fattiness, greasy film (after feeling), farm, butter, cream, persistence of aroma, sour, bitter, umami, astringency, and the persistence of taste. The definition of each descriptor is provided in Table 1. The definitions of the texture attributes were largely based on the ISO 5492: 2008 standard. Aroma descriptors were illustrated with fresh food products (e.g., fresh butter for butter aroma). Sapid compounds in aqueous solutions were used to illustrate taste characteristics (e.g., quinine for a bitter taste). An exception was made for the fattiness attribute, which should reflect a global perception of fat content. Even if this descriptor was used efficiently by the panel, it was not possible to describe clearly the assessment protocol for this sensation during the training period. However, the panelists agreed with the proposed definition: property relative to the perception of the quantity of fat in the product.

After the training phase, six measurement sessions were held. Samples of the same cottage cheese that were evaluated at 7 and $15{ }^{\circ} \mathrm{C}$ were considered as two different 
Table 1 Definition of the 14 sensory attributes

\begin{tabular}{|c|c|}
\hline Descriptor & Definition \\
\hline Perceived temperature & Perceived temperature \\
\hline Thickness & $\begin{array}{l}\text { Property relative to resistance to flow. Thickness was evaluated with a preset } \\
\text { amount of product (equivalent to a spoon). Intensity of thickness was evaluated } \\
\text { by compressing the cottage cheese between tongue and palate and by evaluating } \\
\text { the strength required to allow the product to flow on sides of the tongue }\end{array}$ \\
\hline Fattiness & Property relative to the perception of the quantity of fat in the product \\
\hline $\begin{array}{l}\text { Greasy film } \\
\quad \text { (after feel) }\end{array}$ & $\begin{array}{l}\text { Property relative to lubricity. The intensity of the greasy film was evaluated after } \\
\text { swallowing product by rubbing the tongue against the palate (greasy feeling in } \\
\text { mouth) }\end{array}$ \\
\hline $\begin{array}{l}\text { Remaining quantity in } \\
\text { mouth }\end{array}$ & $\begin{array}{l}\text { Remaining quantity in mouth was evaluated with a preset amount of product } \\
\text { (equivalent to a spoon). Residual amount of product in mouth after swallowing }\end{array}$ \\
\hline Farm & Aroma evoking raw milk, cow, and farm/barn \\
\hline Butter & Aroma evoking butter. Reference sample: butter at room temperature \\
\hline Cream & Aroma evoking cream. Reference sample: double cream at room temperature \\
\hline $\begin{array}{l}\text { Persistence of the } \\
\text { aroma }\end{array}$ & The time during which aroma (global sensation) is perceptible, after swallowing \\
\hline Sourness & Acid taste. Reference sample: aqueous solution of citric acid $\left(0.75\right.$ g. $\left.\mathrm{L}^{-1}\right)$ \\
\hline Bitterness & Bitter taste. Reference sample: aqueous solution of quinine chlorhydrate (15 mg. $\left.\mathrm{L}^{-1}\right)$ \\
\hline Umami & $\begin{array}{l}\text { Taste produced by dilute aqueous solutions of a certain kind of amino acid or } \\
\text { nucleotide such as monosodium glutamate. Reference sample: aqueous } \\
\text { solution of monosodium glutamate }\left(0.4 \text { g. } \mathrm{L}^{-1}\right)\end{array}$ \\
\hline Astringency & $\begin{array}{l}\text { Complex sensation accompanied by shrinking, drawing, or puckering of } \\
\text { the mucosal surface in the mouth, produced by substances such as sloe tannins }\end{array}$ \\
\hline Persistence of taste & The time during which taste (global sensation) is perceptible, after swallowing \\
\hline
\end{tabular}

products to create the experimental design, which therefore contained 14 products. All of the products were evaluated in triplicate. For each replicate, the products were randomly divided into two blocks (seven products evaluated per session), and the samples were presented in a randomized order.

\subsection{Statistical analysis}

All of the data (zero to ten scores) were exported into the SAS® software (SAS Institute, Cary, NC, USA) for analysis.

Performance tests were conducted using the CAP (Control of Assessors' Performance) method, which produces a summary table that assesses the performance of the group and of each panelist (Schlich 1997).

For each descriptor, analyses of variance (ANOVA) were performed using the GLM procedure, according to the following model: intensity $=$ panelist + product + temperature + panelist*product + panelist*temperature + product*temperature + error (random panelist factor). Note that the product factor considered independently from the temperature factor in the ANOVA model is mostly driven by fat level because, except for the three $1 \%$ fat cottage cheeses $(\mathrm{F} 1, \mathrm{~F} 1+$, and $\mathrm{F} 1++)$, fat content was different for all products. This aspect was considered during the interpretation of the ANOVA 
results. When the product effect was significant, multiple comparisons of the means were performed using the Student-Newman-Keuls (SNK) method $(\alpha=0.05)$. Student's $t$ tests for two independent samples were performed $(\alpha=0.05)$ in a few cases, for example, to compare the intensity of a descriptor for flavored and non-flavored products. The multidimensional representation selected to present the main sensory characteristics of the cottage cheeses was a Biplot (the superimposition of observation components and variable loadings multiplied by a constant) generated from the principal component analysis (PCA) performed on the covariance matrix (Gabriel 1971). A multiple linear regression analysis (upward stepwise model) was performed to find out how well the variability of fat content could be predicted by the intensity of one or several of the sensory characteristics evaluated during the sensory profile analysis.

\section{Results and discussion}

The performance of the panelists during the measurement phase was evaluated. The results showed that one of the 16 panelists was not as efficient as the others (poor discriminatory power, lack of repeatability); consequently, the results from this panelist were not considered in subsequent analyses. The effect of the panelist factor was significant for all descriptors, indicating inter-individual differences, which is almost always the case for sensory profile data. These inter-individual differences are fully taken into account through the panelist factor, and results for the other factors remain interpretable.

The results of the ANOVA (Table 2) show that 11 out of the 14 descriptors were influenced by the fat content (or by the added flavor) but not by the tasting temperature. Perceptions of cream aroma, greasy film, and fattiness increased with increasing fat content, and in general, significant differences between the five levels of fat could be observed (Table 3). Conversely, bitterness and astringency decreased with increasing fat content. For these five descriptors, the relationship with fat content was easily modeled using linear regressions, with a very good adjustment quality for the models (cream aroma $=0.4 *$ fat content $+2.4, R^{2}=0.97$; greasy film $=0.3 *$ fat content +3.5 , $R^{2}=0.96$; fattiness $=0.3 *$ fat content $+4.0, R^{2}=0.96$; astringency $=-0.1 *$ fat content + $2.4, R^{2}=0.87$; bitterness $=-0.2 *$ fat content $\left.+2.9, R^{2}=0.81\right)$. The persistence of aroma increased with increasing fat content, but for this descriptor, the correlation was better without the flavored samples included in the analysis (persistence of aroma $=0.3 *$ fat content $+3.1, R^{2}=0.99$ ). It is interesting to note the almost perfect linear relationship between the descriptor greasy film and fattiness $\left(y=1.1 x+0.1 ; R^{2}=0.99\right)$. This indicates that subjects roughly assigned the same score for both descriptors. This result suggests that the greasy film descriptor represents an important part of perceiving fattiness (multidimensional perception) or is a good predictor of fat content in cottage cheeses. The significant product effect observed for the descriptor farm aroma and umami taste was mainly related to the flavored samples. Indeed, samples with the added cream flavor had a more intense farm aroma and umami taste than the other samples (mean value 3.2 versus $1.9, t=3.6, P<0.001$ ). Moreover, the intensities for the descriptor cream aroma and fattiness were almost the same for the flavored samples $(\mathrm{F} 1+$ and $\mathrm{F} 1++)$ and for the corresponding unflavored sample (F1), meaning that the added cream flavor did not directly influence the perceived cream aroma intensity but 
Table 2 ANOVA results for product and temperature factors and for the product*temperature interaction ( $F$ and $P$ values)

\begin{tabular}{|c|c|c|c|c|}
\hline Descriptor & Source & Product & Temperature & Product*temperature \\
\hline \multirow[t]{2}{*}{ Perceived temperature } & $F$ & 0.8 & 111.7 & 1.1 \\
\hline & $P$ value & 0.5677 & $<0.001$ & 0.344 \\
\hline \multirow[t]{2}{*}{ Thickness } & $F$ & 1.0 & 50.6 & 0.7 \\
\hline & $P$ value & 0.401 & $<0.001$ & 0.673 \\
\hline \multirow[t]{2}{*}{ Remaining quantity in mouth } & $F$ & 0.8 & 24.1 & 0.7 \\
\hline & $P$ value & 0.563 & $<0.001$ & 0.615 \\
\hline \multirow[t]{2}{*}{ Fattiness } & $F$ & 17.4 & 0.0 & 0.7 \\
\hline & $P$ value & $<0.001$ & 0.852 & 0.683 \\
\hline \multirow[t]{2}{*}{ Greasy film } & $F$ & 18.1 & 0.1 & 1.2 \\
\hline & $P$ value & $<0.001$ & 0.722 & 0.312 \\
\hline \multirow[t]{2}{*}{ Farm } & $F$ & 4.0 & 0.6 & 2.0 \\
\hline & $P$ value & 0.001 & 0.443 & 0.073 \\
\hline \multirow[t]{2}{*}{ Butter } & $F$ & 3.0 & 0.2 & 0.4 \\
\hline & $P$ value & 0.011 & 0.692 & 0.846 \\
\hline \multirow[t]{2}{*}{ Cream } & $F$ & 23.0 & 0.2 & 0.7 \\
\hline & $P$ value & $<0.001$ & 0.688 & 0.671 \\
\hline \multirow[t]{2}{*}{ Persistence of aroma } & $F$ & 10.5 & 0.4 & 1.2 \\
\hline & $P$ value & $<0.001$ & 0.541 & 0.328 \\
\hline \multirow[t]{2}{*}{ Sour } & $F$ & 3.4 & 0.7 & 0.8 \\
\hline & $P$ value & 0.004 & 0.417 & 0.557 \\
\hline \multirow[t]{2}{*}{ Bitter } & $F$ & 9.9 & 1.4 & 0.3 \\
\hline & $P$ value & $<0.001$ & 0.255 & 0.910 \\
\hline \multirow[t]{2}{*}{ Umami } & $F$ & 4.8 & 0.4 & 0.8 \\
\hline & $P$ value & $<0.001$ & 0.526 & 0.568 \\
\hline \multirow[t]{2}{*}{ Astringency } & $F$ & 13.0 & 2.9 & 1.0 \\
\hline & $P$ value & $<0.001$ & 0.108 & 0.445 \\
\hline \multirow[t]{2}{*}{ Persistence of taste } & $F$ & 4.3 & 0.0 & 0.9 \\
\hline & $P$ value & 0.001 & 0.994 & 0.480 \\
\hline
\end{tabular}

rather enhanced the farm and umami notes. The added cream flavor used was specially designed for this study. It was expected that perceptions of fattiness could be enhanced by such a cream-related aroma, but this effect could not be verified in this study. One reason for this could be that the aroma composition was a rather simple mixture that was not fully appropriate for evoking a typical cream aroma in cottage cheese. Moreover, it should be noted that the profiling technique used here required that the panelists follow a strict analytical approach, which was shown to thoroughly alter cross-modal interactions due to top-down attentional effects (Prescott and Murphy 2009), but also the perception of low-complexity odor mixtures (Le Berre et al. 2008). All of the other descriptors (butter, sourness, and persistence of taste) were significantly influenced by fat content, but differences between the samples could be 


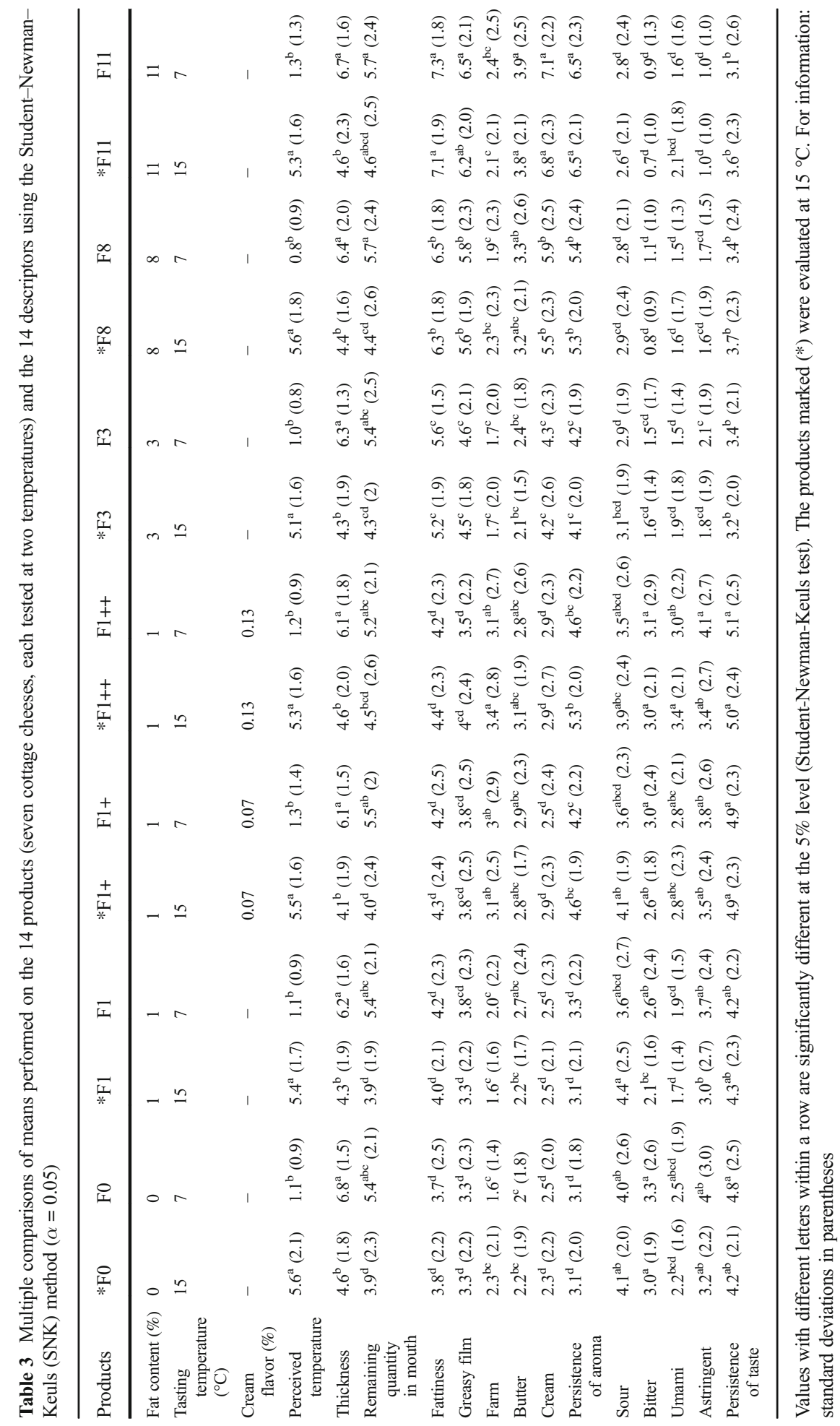


clearly identified only when comparing the high-fat and low-fat samples. Samples with a fat content of $8 \%$ and above were more intense in butter aroma than the unflavored samples containing $3 \%$ or less fat. The intensity scores of the flavored samples fell between the scores of these two groups, meaning that the added cream flavor contributed to the butter note. For the sourness and persistence of taste descriptors, there was a gap between samples with a fat content of $1 \%$ or less and samples with $3 \%$ or more: the high-fat samples were perceived as less sour. This finding is consistent with the lactic acid content of the samples $(12.8,12.6,11.9,10.5$, and $9.9 \mathrm{~g}$ of lactic acid per liter, respectively, for F0, F1, F3, F8, and F11) and with the fact that titratable acidity partly explains sour taste intensity (Da Conceicao Neta et al. 2007). This lower sourness may explain the lower persistence of taste. It should be noted that the thickness of the different cottage cheese samples was not influenced by fat content; therefore, for this type of product, thickness did not appear to be involved in the discrimination among samples varying in fat content.

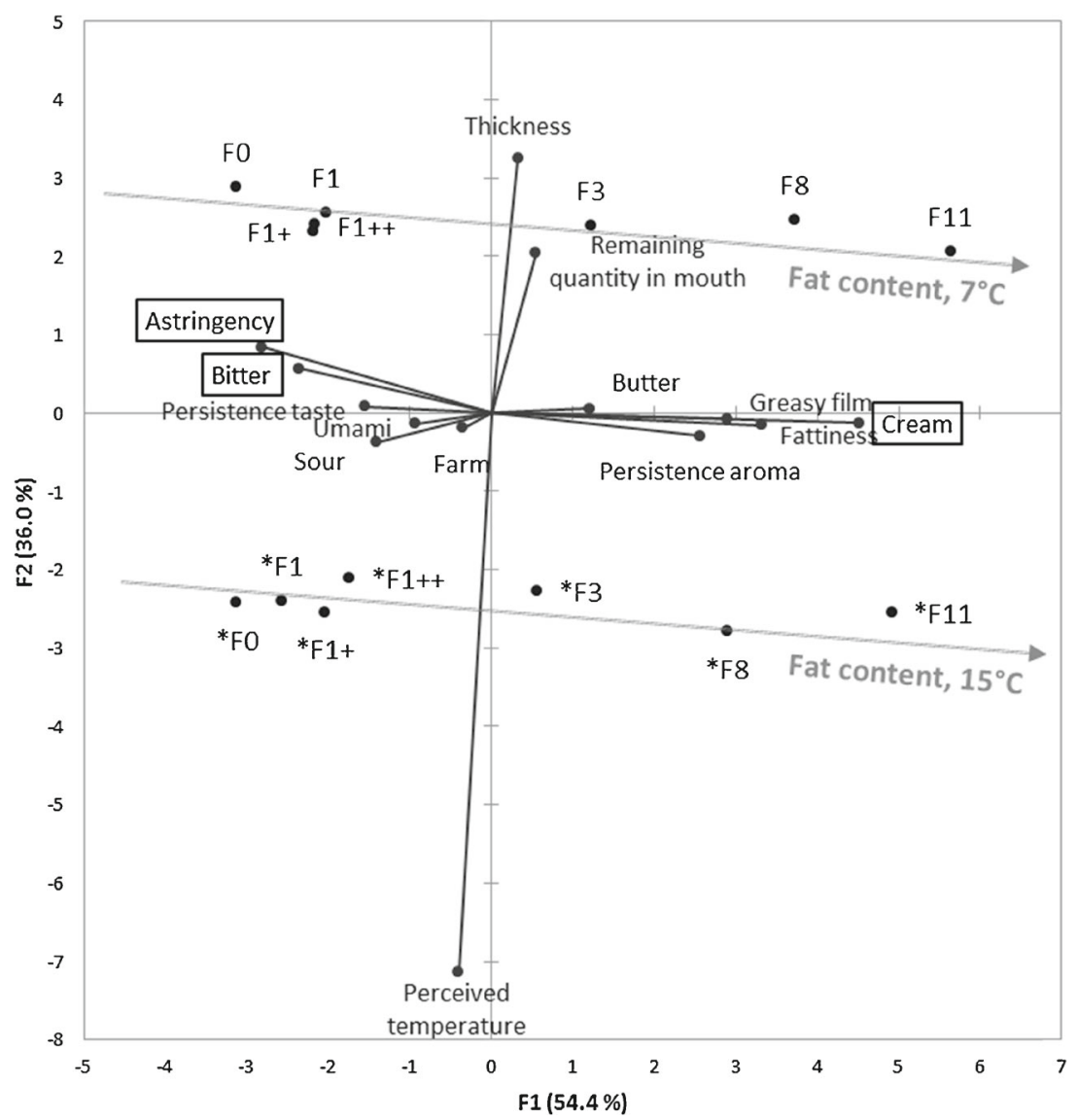

The products marked $\left(^{*}\right)$ were evaluated at $15^{\circ} \mathrm{C}$. The words in the boxes are the main descriptors associated with fat content (multiple linear regression).

Figure 1 Biplot representation from the PCA performed on the covariance matrix. The 14 products (seven cottage cheeses, each tested at two temperatures) and the 14 descriptors 
The results of the PCA (Fig. 1) highlight that cream aroma, astringency, and bitterness contribute to the first axis, along which the cottage cheese samples are distributed according to their fat content. These findings are also supported by the results of a multiple linear regression, which shows that these three descriptors were the ones primarily associated with fat content. Cream aroma was positively related to fat content, whereas astringency and bitterness were negatively related to fat content (fat content $=2.5+$ $0.7 *$ cream $-0.4 *$ bitter $-0.3 *$ astringent; $R^{2}=0.45$; ANOVA of the model, $\left.p<0.0001\right)$. Regardless of the added flavor, the results show that the perceived cream aroma (naturally occurring in commercial cottage cheeses, not due to the added flavor) is part of the main set of descriptors associated with fat content, thus, strongly suggesting the actual contribution of olfactory cues to overall perceptions of fat. Bitterness and astringency are also some of the main descriptors associated with fat content. A masking effect might partly explain the decrease in the intensity of these two descriptors with an increase in fat content (Metclaf and Vickers 2002). It would therefore be interesting to investigate the possibility of an enhancement of the cream aroma combined with a reduction of bitterness and astringency as a way to maintain the perception of fat while reducing fat content. Nevertheless, this is not an easy task because effective strategies for decreasing the perception of bitterness and astringency in food products are limited (Keast 2008).

The comparison of the sensory profiles obtained at the two tasting temperatures ( 7 and $15{ }^{\circ} \mathrm{C}$ ) provides valuable information about how this type of dairy product can be perceived in different contexts (straight from the refrigerator or several tens of minutes after being removed, as in a cafeteria). Only three out of 14 descriptors varied significantly with tasting temperature. As expected, there was a highly significant difference between the perceived temperature of the samples evaluated at 7 and $15{ }^{\circ} \mathrm{C}$. This $8{ }^{\circ} \mathrm{C}$ difference led to a difference of more than four points on the scale $(5.4 / 10$ on average for samples served at $15^{\circ} \mathrm{C}$ versus $1.1 / 10$ on average for samples served at $7{ }^{\circ} \mathrm{C}, t=22.4$, $P<0.0001$ ). The samples evaluated at $7^{\circ} \mathrm{C}$ were perceived to be thicker and as leaving a larger residual quantity of product in the mouth after swallowing. This can be explained by the higher viscosity of cottage cheese at the lower temperature. These three descriptors strongly contribute to the second axis of the PCA performed on the full set of results (Fig. 1) and, therefore, to the separation between the samples evaluated at 7 and $15^{\circ} \mathrm{C}$ (marked on Fig. 1 by *). Given the significant variation of the tasting temperatures, one might have expected differences in terms of aroma due to effects on the volatility of some chemical compounds. An additional predicted effect could be that with the temperatureinduced decrease in thickness, these compounds would be more readily released from the matrix (Gierczynski et al. 2011). Moreover, the lower viscosity paired with a higher temperature might facilitate the taste compounds entering the saliva and hence reaching the taste buds (Engelen et al. 2003). However, the results of this work showed that this was not the case for cottage cheese because the perception of olfactory descriptors (cream, butter, and farm aromas) was not different between the two temperatures. The persistence of aroma was also unaffected by the tasting temperature. Similarly, the intensity of sour, bitter, and umami taste, and even astringency, did not vary significantly between the two tasting temperatures (Table 2). However, Engelen et al. (2003) showed that after a mouth rinse with water at 10,35 , and $55^{\circ} \mathrm{C}$, the oral temperature gradually changed back to baseline $\left(35^{\circ} \mathrm{C}\right)$ after approximately $2 \mathrm{~min}$. It can therefore be assumed that, once in the mouth, cottage cheese warmed rapidly to reach the temperature of the mouth. This could have reduced the expected temperature effect, especially 
as taste and aroma descriptors were systematically evaluated at the end of the sample evaluation, namely, after the texture attributes. In contrast, perceived thickness, which was evaluated first, was strongly influenced by tasting temperature. On average, the viscosity values (Pa.s) at $7{ }^{\circ} \mathrm{C}$ were $37 \%$ higher than the viscosity values obtained at $15{ }^{\circ} \mathrm{C}$.

\section{Conclusion}

The primary outcome of this study is a full description of the sensory characteristics related to fat content in cottage cheese. The results show that the perceived differences among cottage cheeses varying in fat content were based on a range of differences related to aroma (mainly cream aroma), taste (mainly bitterness), trigeminal sensation (astringency), and texture (greasy film). The secondary outcome relates to the modulation of the sensory characteristics of cottage cheese as a function of tasting temperatures. The results show that the tasting temperature did not impact taste, aroma, or astringency. However, thickness was strongly modified by the tasting temperature, regardless of the fat content of cottage cheeses. These results could be useful in better understanding fat perception in real, semi-solid food products and in pursuing the goal of formulating reduced-fat semi-solid dairy products.

Acknowledgments The authors thank Betty Hoffarth for her technical assistance during the sessions with the subjects. Firmenich S.A. is thanked for providing the cream flavor. This work was supported by grants from the Regional Council of Burgundy, the FEDER (European Regional Development Fund), and the Carnot Institute Qualiment ${ }^{\circledR}$. RS thanks the Giract Organization PhD Flavor Research Programme for a first-year Bursary Award.

\section{Compliance with ethical standards}

Conflict of interest The authors declare that they have no conflict of interest.

Statements of compliance with ethical requirements The study was conducted according to the Declaration of Helsinki and was approved by the local ethics committee ("Comité Consultatif de Protection des Personnes dans la Recherche Biomédicale de Bourgogne”), ID RCB 2013-A01378-37.

\section{References}

Da Conceicao Neta ER, Johanningsmeier SD, McFeeters RF (2007) The chemistry and physiology of sour taste-a review. J Food Sci 72:33-38

Engelen L, de Wijk RA, Prinz JF, Janssen AM, Weenen H, Bosman F (2003) The effect of oral and product temperature on the perception of flavor and texture attributes of semi-solids. Appetite 41:273-281

Gabriel KR (1971) The biplot graphic display of matrices with application to principal component analysis. Biometrika 58:453-467

Gierczynski I, Guichard E, Laboure H (2011) Aroma perception in dairy products: the roles of texture, aroma release and consumer physiology. A review. Flavour Fragr J 26:141-152

ISO (International Organization for Standardization) (1985) ISO 6564 sensory analysis, methodology, flavour profile methods. ISO, Geneva. 
ISO (International Organization for Standardization) (2008) ISO 5492 sensory analysis, vocabulary. ISO, Geneva.

ISO (International Organization for Standardization) (2012) ISO 11132 sensory analysis, guidelines for monitoring the performance of a quantitative sensory panel. ISO, Geneva.

ISO/TS 11869 (IDF/RM 150) (2012) Fermented milks - determination of titratable acidity - potentiometric method. ISO, Geneva.

Keast RSJ (2008) Modification of the bitterness of caffeine. Food Qual Prefer 19:465-472

Le Berre E, Thomas-Danguin T, Béno N, Coureaud G, Etiévant P, Prescott J (2008) Perceptual processing strategy and exposure influence the perception of odor mixtures. Chem Senses 33:193-199

Le Calvé B, Saint-Léger C, Babas R, Gelin J-L, Parker A, Erni P, Cayeux I (2015) Fat perception: how sensitive are we? J Texture Stud 46:200-211

Mattes RD (2009) Is there a fatty acid taste? Annu Rev Nutr 29:305-327

Mela DJ (1988) Sensory assessment of fat content in fluid dairy products. Appetite 10:37-44

Metclaf KL, Vickers ZM (2002) Taste intensities of oil-in-water emulsions with varying fat content. J Sens Stud 17:379-390

Prescott J, Murphy S (2009) Inhibition of evaluative and perceptual odour-taste learning by attention to the stimulus elements. Q J Exp Psychol 62:2133-2140

Schlich P (1997) CAP : une méthode et un outil de contrôle rapide et synthétique des performances des sujets en évaluation sensorielle descriptive. Paper presented at Versailles, 3-5 december 1997.

Schoumacker R, Martin C, Thomas-Danguin T, Guichard E, Le Quéré J-L, Labouré H (2016) Fat perception in cottage cheese: the contribution of aroma and tasting temperature. Food Qual Prefer, in press doi: 10.1016/j.foodqual.2016.04.00. (http://www.sciencedirect.com/science/article/pii/S0950329316300751).

Thomas-Danguin T, Rouby C, Sicard G, Vigouroux M, Farget V, Johansson A, et al. (2003) Development of the ETOC: a European test of olfactory capabilities. Rhinology 41:142-151 